\title{
USO DOS CONHECIMENTOS PRÉVIOS DOS ESTUDANTES: UMA EXPERIÊNCIA NA FORMAÇÃO INICIAL DE PROFESSORES DE FÍSICA
}

\author{
C. B. HYGINO*, G. F. ROSA, L. J. CALLEGARIO, L. P. COSTA, V. L. O. ALVES e M. P. LINHARES \\ Centro de Ciências e Tecnologia-Universidade Estadual do Norte Fluminense \\ cacahygino@yahoo.com.br*
}

Artigo submetido em setembro/2014 e aceito em dezembro/2015

DOI: $10.15628 /$ holos.2015.2403

\section{RESUMO}

Nesta pesquisa apresentamos uma proposta didática desenvolvida na formação inicial de professores de física, ao longo de três disciplinas obrigatórias de um Curso de Licenciatura em Física, que buscou a evolução do conhecimento profissional docente, de acordo com os modelos didáticos tradicional, espontaneísta e investigativo. Para o desenvolvimento da proposta didática foi utilizado, como estratégia de ensino, o método de estudo de caso, focalizando questões relevantes da prática docente. Analisamos, no presente artigo, o estudo de caso intitulado: "Os conhecimentos prévios no processo de aprendizagem de Física", desenvolvido na disciplina Estratégias para o Ensino de Física II, que teve como objetivo identificar as concepções dos futuros docentes sobre as formas de acessar e considerar os conhecimentos prévios dos alunos. Os dados foram coletados a partir das respostas de seis licenciandos, nos passos inicial e final do estudo de caso. A análise do conteúdo das respostas obtidas indicou que, ao fim do processo, os futuros docentes apresentaram concepções mais próximas dos modelos desejáveis.

PALAVRAS-CHAVE: conhecimentos prévios, formação inicial, ensino de física.

\section{USING THE PREVIOUS KNOWLEDGE OF STUDENTS: AN EXPERIENCE IN THE INITIAL TRAINING OF PHYSICS TEACHERS}

\begin{abstract}
In this research we present a didactic proposal developed in the initial training of physics teachers comprising three compulsory subjects of a Degree in Physics. This study aims to understand the evolution of professional teaching knowledge based on the traditional, spontaneous and investigation models. For the development of the didactic proposal the case study method was used as a teaching strategy, focusing on relevant issues of teaching practice. The present article provides an analysis of the case study entitled "Ideas in
\end{abstract}

Physical previous learning process", which was developed in the subject Strategies for Physical Education II. We aimed to identify the conceptions of future teachers regarding the different ways of accessing and considering the previous knowledge of students. Data were collected from the responses of five undergraduate students in the initial and final stages of the case study. The content analysis of the collected responses indicated that at the end of the process the conceptions held by the future teachers were closer to the desirable models.

KEYWORDS: previous knowledge, initial training, physics teaching 


\section{INTRODUÇÃO}

Ao fazer uma análise da prática docente dos professores de Física, observa-se a ênfase na memorização de fatos, fórmulas e a resolução de exercícios repetitivos, o que pouco contribui com a formação de alunos críticos, como orientam os documentos oficiais da educação básica (BRASIL, 1999). Esta prática, tão amplamente utilizada, advém do fato de que os professores reproduzem os métodos de ensino de Física que vivenciam em sua formação, ou seja, reproduzem o que seus mestres lhe ensinaram. Além disso, os professores, em geral, não se sentem motivados e apoiados para desenvolver práticas diferenciadas e inovações em suas aulas (BORGES, 2006).

É comum observar que, na maioria dos cursos de licenciatura em Física, os licenciandos adquirem conhecimentos específicos, trabalhados na sua forma acabada. Como bem fundamentam Delizoicov, Angotti e Pernambuco (2002), os cursos de formação de professores, de modo geral, privilegiam o aprendizado de conteúdos específicos de sua licenciatura. Estes conteúdos são assimilados de forma fragmentada em disciplinas separadas, durante sua graduação. Para superar a suposta oposição entre 'conteudismo' e 'pedagogismo', os currículos de formação de professores devem contemplar espaços, tempos e atividades adequadas, que facilitem, aos licenciandos, a permanente transposição didática, isto é, a transformação dos objetos de conhecimento em objetos de ensino.

Neste sentido, as práticas docentes precisam de mudanças. É necessário favorecer momentos de formação inicial, em que seja possível mostrá-los a necessidade de um ensino diferente do tradicional, reconhecendo-os como sujeitos responsáveis e fundamentais pelas tão desejadas mudanças em nosso sistema educacional (GUIMARÃES, ECHEVERRÍA E MORAES, 2006). Desse modo, acreditamos que os modelos formativos devem propiciar aos docentes o questionamento de suas concepções e de suas práticas relacionadas a problemas fundamentais (o que ensinar e para que, que atividades realizar na sala de aula, como acompanhar a evolução dos alunos) e como implementar estas mudanças.

Diante deste contexto, colocamos a seguinte questão: como os futuros professores podem evoluir seus conhecimentos didático-metodológicos e adquirir meios para que esta evolução seja capaz de proporcionar mudanças em suas práticas?

Na tentativa de responder a esta questão, desenvolvemos uma investigação com alunos do curso de Licenciatura em Física, em três disciplinas da grade regular, com o objetivo de favorecer a evolução dos conhecimentos profissionais docentes, a partir da reflexão-ação sobre suas práticas. As disciplinas Estratégias para o Ensino de Física I, II e III têm como objetivo associar teoria e prática e conhecimentos científicos da área de Física e conhecimentos pedagógicos. As atividades de cunho investigativo têm como eixo principal o método do estudo de caso, considerada a estratégia mais adequada para alcançar os objetivos das disciplinas. Durante a concretização dos estudos foram realizadas atividades práticas e de reflexão, incluindo leituras e discussão de artigos científicos. Além disso, cada licenciando deve planejar e apresentar uma aula de Física; como uma reflexão de sua prática, deve elaborar um texto que relate sua aula, o que deveria mudar e o que deve permanecer, ainda deveria indicar quais as alternativas de mudanças (HYGINO, MOURA e LINHARES, 2014). 
Neste trabalho, apresentamos as análises referentes às respostas dos licenciandos, matriculados na disciplina Estratégias para o Ensino de Física II, quanto aos questionamentos apresentados em um estudo de caso acerca de suas concepções sobre as formas de acessar e a importância de considerar o conhecimento prévio dos alunos, a fim de possibilitar o surgimento de modelos didáticos mais complexos e avançados, que possam admitir uma prática inovadora.

\section{MODELOS DIDÁTICOS NA FORMAÇÃO DOCENTE EM CIÊNCIAS}

O fazer pedagógico de cada professor, ou seja, "o jeito" como cada professor articula sua aula está diretamente relacionado ao seu saber ou conhecimento profissional. Desse modo, este fazer pedagógico reflete o modelo de apoio do professor que, de acordo com Harres et al (2005, p. 9) "seria a seleção de elementos relacionados entre si e que devem ser levados em conta na abordagem de um processo". No que se refere à educação, os "modelos didáticos" interpretam a realidade da sala de aula e compreendem as concepções dos professores sobre o conhecimento, sobre a educação e sobre o mundo.

$\mathrm{Na}$ literatura podem ser identificados vários modelos didáticos que variam, desde a predominância do modelo tradicional até tendências mais transformadoras. De acordo com Porlán e Rivero (1998), as atuações e concepções dos professores, frente ao processo de ensinoaprendizagem, podem ser representadas por meio de quatro modelos didáticos: 1) o tradicional, 2) o tecnológico e 3) o espontaneísta, caracterizados como modelos de transição, e 4) o modelo investigativo.

O modelo didático tradicional caracteriza-se pela transmissão de conhecimentos, em que os conteúdos são pensados em sequências lineares e rígidas. A metodologia é a transmissão verbal do professor e uso, quase exclusivo, do livro-texto. Avalia-se a memorização mecânica dos conteúdos e o professor tem papel ativo, enquanto o aluno, passivo.

O modelo tecnológico tem o objetivo de ensinar adequadamente as ciências, utiliza-se de materiais didáticos atualizados e tem planejamento metodológico rigoroso. A avaliação tem como objetivo quantificar a aprendizagem e verificar a eficiência desta sistemática de ensino, o aluno tem, ainda, papel passivo.

No modelo espontaneísta, o conhecimento dos alunos tem ênfase, os conteúdos atendem aos seus interesses, as atividades não são previamente planejadas, valoriza-se apenas a experiência dos professores, a avaliação se dá através da participação dos alunos.

O modelo investigativo, por sua vez, propõe um ensino no qual, tanto alunos quanto professores, exercem um papel ativo. Enfatizam-se as situações-problema que exigem dos alunos posturas investigativas, em que devem elaborar hipóteses e propor soluções. As atividades são contextualizadas, com temas socialmente relevantes e com incentivo da atuação dos alunos. A avaliação tem como objetivo identificar as dificuldades dos alunos e promover reflexões sobre a evolução dos estudantes.

Para Porlán e Rivero (1998), o processo de formação de professores de ciências deve se guiar por hipóteses de progressão, ou seja, devem estar centradas em estratégias que favoreçam a evolução dos conhecimentos profissionais docentes, a fim de que possa ocorrer uma mudança concreta da prática dos professores. 
Segundo esses autores, o conhecimento é constituído pelo conjunto de crenças, conhecimentos específicos, rotinas e técnicas que, na sua forma desejável, envolveria a integração dessas dimensões de forma complexa, crítica, evolutiva e investigativa em sala de aula.

Além disso, deve-se considerar as ideias sobre ensino e aprendizagem que os professores apresentam antes de iniciar seu processo de formação, sendo essas, possivelmente, o ponto de partida dos processos formativos. Portanto, a formação dos professores seria um processo de (re)construção gradual e contínua de seu conhecimento profissional, cuja intencionalidade destina-se à construção de estratégias para a superação dos problemas da prática docente. Esta construção, concebida evolutivamente, deve desenrolar-se em um contexto de explicitação, reflexão e discussão sobre seu conhecimento profissional prévio e seu confronto com novas concepções, para possibilitar mudanças conceituais, metodológicas e atitudinais dos professores (HARRES et al, 2005).

Neste caso, a evolução é entendida como a passagem de concepções e ações docentes, inicialmente simples e, na maioria das vezes, implícitas, relacionadas com o modelo didático tradicional, para outras progressivamente mais complexas e conscientes, "embasadas em uma visão integradora das relações entre ciência, ideologia e cotidianidade e no desenvolvimento dos princípios de autonomia, diversidade e negociação rigorosa e democrática de significados" (PORLÁN e RIVERO, 1998, p. 56).

Desta perspectiva, alguns dos âmbitos de desenvolvimento profissional, mais significativos para os professores de ciências das etapas educativas obrigatórias são:

(a) O que sabem os professores sobre os conteúdos a ensinar? (b) O que sabem os professores sobre o que sabem os alunos? (c) O que e para que ensinar em ciências? (d) Como ensinar? (e) O que e como avaliar?

Desse modo, apoiados nas orientações de Porlán e Rivero (1998), desenvolvemos uma proposta curricular para a formação de professores de Física que reconhece a necessidade de disponibilizar recursos para o futuro docente enfrentar uma variedade de situações, tornando-o capaz de identificar e propor soluções aos problemas enfrentados no cotidiano da sala de aula.

\section{A DISCIPLINA ESTRATÉGIAS PARA O ENSINO DE FÍSICA II}

O contexto desta pesquisa constitui-se em uma série de três disciplinas, denominadas Estratégias para o Ensino de Física I, II e III, oferecidas obrigatoriamente para o 3으, 5으 e 7o períodos da Licenciatura em Física de uma universidade estadual do estado do Rio de Janeiro, composta por 8 períodos. Estas disciplinas possuem carga horária de 34 horas semestrais e são ministradas uma vez por semana durante 2 horas, no período noturno. As disciplinas buscam integrar o conhecimento específico da Física com a dimensão pedagógica da atuação docente e têm como objetivo favorecer a postura reflexiva, crítica, aberta à mudança e em permanente evolução profissional.

A proposta didática adotada nas disciplinas tem como eixo principal o método de estudos de caso. Apresenta-se como narrativas ou como um relato de situações problemáticas que, neste caso, constituem-se em problemas da prática docente. No desenvolvimento de um estudo de caso, os futuros professores são incentivados a buscar soluções para os problemas da prática 
profissional, partindo de seus conhecimentos prévios. Ao longo do desenvolvimento da proposta estes conhecimentos são articulados a diferentes conhecimentos teóricos e práticos, a fim de propor novas soluções.

Um estudo de caso, em geral, apresenta três passos. No primeiro realiza-se uma leitura do texto e são apresentadas as soluções aos problemas propostos, com base em conhecimentos prévios; no segundo são encaminhadas leituras, experimentos, discussões, dentre outras práticas, com o objetivo de aprofundar as questões propostas inicialmente e, por fim, no terceiro passo deve-se retomar as questões iniciais e respondê-las, embasados nos conhecimentos adquiridos ao longo do processo (REIS e LINHARES, 2008).

Em cada uma das disciplinas são elaborados, pelo professor/pesquisador, estudos de caso que tratam de problemas relevantes da prática docente, são propostas, ainda, atividades investigativas desencadeadas a partir do problema exposto no estudo de caso. Trataremos especificamente da disciplina Estratégias para o Ensino de Física II, realizada no segundo semestre letivo de 2012, pois uma das atividades propostas será alvo de análise no presente trabalho. Nesta disciplina, matricularam-se 6 licenciandos.

A disciplina Estratégias para o Ensino de Física II teve como objetivo discutir sobre o uso dos conhecimentos prévios dos alunos, pois, assim, como destacam Garcia e Porlán (2000), o reconhecimento e a utilização didática do conhecimento dos alunos é um aspecto do conhecimento profissional dos professores com alto poder formativo.

A investigação sobre concepções prévias tem sido objeto de pesquisa desde a década de 1970 e ganhou força nos anos de 1980, com o movimento das concepções alternativas. Em geral, esses estudos revelam que crianças, adolescentes e professores possuem diversas ideias que são inconsistentes com o conhecimento científico. De acordo com Mortimer (1996), estas ideias não devem ser simplesmente abandonadas pelos educadores, mas devem ser utilizadas, podendo ser trabalhadas de diferentes formas.

Quadro1: Texto do estudo de caso: “Os conhecimentos prévios no processo de aprendizagem de Física”,

Estudo de caso: Os conhecimentos prévios no processo de aprendizagem de Física

Em uma escola do interior do estado do Rio de Janeiro, os professores de física se reuniram no início do ano letivo para discutirem como seriam planejadas as aulas para os alunos da primeira série do ensino médio, mediante o novo currículo mínimo de Física que seria adotado a partir do ano de 2012. Para esta série o currículo contempla os seguintes tópicos distribuídos em quatro bimestres: (1) Cosmologia - Movimento; (2) Forças; (3) Relatividade restrita e geral; (4) Impulso, momento linear e conservação do momento.

Após as discussões, os professores avaliaram a necessidade de conhecer o conhecimento dos alunos sobre os assuntos a serem abordados a cada bimestre. No entanto, os professores ainda não haviam chegado a um consenso se este seria um caminho adequado e como poderiam investigar o conhecimento dos alunos sobre os tópicos indicados no currículo mínimo.

Caso você estivesse participando desta reunião, que opinião teria sobre as questões:

1- Que conhecimentos você acredita que os alunos possuem sobre os tópicos relacionados? (Escolha um dos tópicos do currículo mínimo).

2- Que instrumentos você utilizaria para conhecer os conhecimentos dos alunos sobre este assunto?

3- Como você utilizaria os conhecimentos dos alunos em seu planejamento de ensino?

Para o trabalho na disciplina foi desenvolvido o estudo de caso intitulado: "Os conhecimentos prévios no processo de aprendizagem de Física", quadro 1, com o objetivo de favorecer o entendimento de que os conhecimentos prévios desempenham um papel importante no processo de aprendizagem, podendo ser trabalhadas de várias maneiras. 
Durante o desenvolvimento do estudo de caso, os licenciandos realizaram leituras de artigos sobre o tema (SEBASTIANY et al, 2009) e também pesquisas bibliográficas sobre concepções alternativas, relacionadas a um conteúdo da segunda série do ensino médio do currículo mínimo do estado do Rio de Janeiro e que fossem aprofundar na disciplina (HYGINO e LINHARES, 2013).

Além disso, também foram realizadas leituras de artigos da área de ensino de ciências, a respeito de diferentes formas de acessar o conhecimento prévio dos alunos, como o uso de desenhos, questionários e mapas conceituais (GENEZINI et al. 2007, IACHEL, LANGHI e SCALVI, 2008; BATISTA E ARAMAN, 2009; KRUMMENAUER, 2010). Nestes trabalhos, os licenciandos puderam conhecer o que são os conhecimentos prévios ou concepções alternativas e diferentes abordagens para tal. Com base em leituras e discussões, cada licenciando deveria planejar e apresentar sua proposta de aula, na forma de uma aula-teste, para os seus colegas da disciplina. Ao fim da aula, foi pedido que os licenciandos elaborassem um texto de reflexão sobre sua aulateste, destacando pontos positivos e negativos, o que deve ser mantido, o que pode ser mudado em sua aula e os motivos. De acordo com Oliveira (2009), o processo de refletir sobre posições assumidas, neste caso a posição de professor, implica trazer à tona noções de subjetividade e identidade. Este processo contribui com a autopercepção e autorreconhecimento de seus procedimentos.

\section{METODOLOGIA}

Assumimos as referências de uma pesquisa-ação como mais apropriada para a metodologia de nossa pesquisa. Segundo Moreira (2002), a pesquisa-ação tem por objetivo a melhoria da prática, levando-se em consideração os resultados e processos.

No estudo de caso "Os conhecimentos prévios no processo de aprendizagem de Física", seis alunos da Licenciatura em Física do 5 o período participaram na busca de soluções para a questão proposta. Os dados da pesquisa foram obtidos a partir das soluções encaminhadas pelos licenciandos nos passos inicial e final do estudo de caso, quando emitiram suas respostas sobre o planejamento de aulas de Física.

Para a análise das respostas dos licenciandos, aos questionários e aos passos inicial e final do estudo de caso, elegemos a análise de conteúdo na abordagem de Bardin (2009). Esta análise é organizada em torno de três etapas consecutivas: i) pré-análise dos textos, ii) exploração do material e iii) tratamento dos resultados, inferência e interpretação (BARDIN, 2009). A pré-análise consiste no primeiro contato com o material, é a fase de organização do material e de começar a elaborar hipóteses e índices que traduzem a frequência observada no tema em questão. A exploração do material consiste, essencialmente, nas operações de codificação do material, isto é, o recorte das Unidades de Significação (US), a enumeração (escolha das regras de contagem) e a classificação (agregação e categorização), em função das regras previamente formuladas. No tratamento dos resultados, o pesquisador de posse dos resultados pode propor inferências e adiantar interpretações a propósitos dos objetivos previstos. 


\section{RESULTADOS}

O estudo de caso "Os conhecimentos prévios no processo de aprendizagem de Física" procurou identificar o que os licenciandos em Física pensam a respeito do conhecimento prévio dos estudantes e se as utilizariam e como as utilizariam em seu planejamento de ensino.

Distribuímos as respostas dos passos inicial e final em duas categorias: "Concepções sobre os conhecimentos prévios dos alunos", que conferem as respostas dos licenciandos que apresentam suas concepções sobre a utilização dos conhecimentos prévios dos alunos no processo de ensino e aprendizagem e "Formas para trabalhar com os conhecimentos prévios dos alunos", que reúne as respostas dos licenciandos sobre como de fato eles pretendem ministrar suas aulas, a partir de e com as ideias iniciais dos estudantes. A fim de preservamos as identidades dos licenciandos, os chamaremos de: F, P, G, L, T e B.

Os dados da categoria "Concepções sobre as os conhecimentos prévios dos alunos" dos passos inicial e final das respostas ao estudo de caso dos licenciandos estão apresentados na tabela 1.

Tabela 1: US dos passos inicial e final da categoria concepções sobre os conhecimentos prévios dos alunos

\begin{tabular}{|l|l|}
\hline \multicolumn{2}{|c|}{ Categoria: concepções sobre os conhecimentos prévios dos alunos } \\
\hline \multicolumn{1}{|c|}{ US passo inicial } & \multicolumn{1}{c|}{ US passo final } \\
\hline Ideias de senso comum $(B, F, G)$ & Ideias aristotélicas $(B, P)$ \\
Ideias relacionadas ao cotidiano $(P, L)$ & Ideias básicas $(G)$ \\
Conhecem pouco $(F, T)$ & Possuem os conhecimentos prévios $(L, P, B)$ \\
\hline
\end{tabular}

Em resposta às questões levantadas na narrativa do estudo de caso, os licenciandos expuseram sobre a existência dos conhecimentos prévios entre os estudantes. De acordo com Pozo e Crespo (1998), as concepções prévias não devem ser consideradas um problema ou obstáculo à aprendizagem.

No passo inicial, quando interrogados sobre a possibilidade de os estudantes apresentarem conhecimentos prévios sobre os conteúdos de estudo, os licenciandos, em suas respostas, classificaram as ideias dos mesmos como sendo de senso comum, ou popular:

Provavelmente poucas, vindas do senso comum e que correm o risco de terem traços aristotélicos (Licenciando B, passo inicial).

Acredito que os conhecimentos prévios dos alunos se baseiam em conhecimentos populares, talvez um misto de ideias embasadas em conhecimentos científicos e não científicos como astrologia com certeza e grande maioria já ouviu falar da teoria do big bang conhece os planetas do sistema solar e as fases da lua, mas tudo isto em nível superficial sem uma base bem elaborada nos conhecimentos científicos (Licenciando F, passo inicial).

Para Driver et al (1999), as formas 'de senso comum' de explicar os fenômenos representam o conhecimento do mundo descrito dentro da cultura do dia-a-dia. Por sua vez, diferem do conhecimento da comunidade científica de várias maneiras. 
Ainda no passo inicial, ao tratarem dos conhecimentos dos estudantes, relacionados aos conteúdos, os licenciandos opinam que estas devem ser simples, demonstrando acreditarem que eles podem não possuir um maior aprofundamento sobre determinados assuntos

Ideias básicas como de forças na mecânica, empurrar um corpo, as coisas do tipo ou até de forças relacionadas à energia elétrica, mas mais focado em mecânica. (Licenciando G, passo inicial)

Os alunos provavelmente possuem uma ideia muito básica sobre cosmologia. Eles devem conhecer conteúdos de planetas, mas somente nomes. Não devem saber nada sobre a influência que cada corpo no universo exerce sobre outro. (Licenciando T, passo inicial)

Percebemos, a partir das respostas dos licenciandos, uma aproximação ao modelo didático tradicional, pois os conhecimentos dos alunos são vistos como o resultado da apropriação dos conteúdos acadêmicos anteriores, visão em que os conhecimentos dos alunos têm pouco valor epistêmico. Nesse caso, está implícita uma concepção de aprendizagem aditiva, na qual se concebe a mente do aluno como se fosse uma folha em branco, sobre a qual poderia escrever o que se quer, armazenando informação (PORLÁN e RIVERO, 1998).

Os licenciandos, em suas respostas, demonstram a importância em estabelecer relações às aplicações no cotidiano dos estudantes:

Os alunos, em relação aos temas dos tópicos relacionados, possuem uma ideia mais superficial direcionando ao tópico forças. Eles podem ter uma ideia mais clara em relação aos demais por usarem por muitas vezes no dia a dia a palavra e relacionariam a questão da força como agente para mover algo, por exemplo. Eles não sabem o significado do tema a fundo, mas devido à praticidade do dia-a-dia em relação à força eles podem ter uma ideia que facilita o aprendizado. (Licencianda L, passo inicial).

De fato, as ideias são julgadas por sua utilidade, para fins específicos ou em situações específicas se, como tal, orientam as ações das pessoas. A busca científica, por outro lado, tem o objetivo adicional de construir um quadro geral e coerente do mundo (DRIVER et al, 1999).

Além disso, as maneiras como os indivíduos experimentam os fenômenos naturais são limitadas pela própria realidade. No que tange às experiências do dia-a-dia das pessoas, os conhecimentos informais são, na maioria das vezes, perfeitamente adequados para interpretar e orientar as ações. Argumentamos, portanto, que os conhecimentos informais não são apenas visões pessoais do mundo, mas refletem uma visão comum, representada por uma linguagem compartilhada. Essa visão compartilhada constitui o'senso comum', uma forma socialmente construída de descrever e explicar o mundo.

No entanto, já no passo final, consideram mais aprofundadas os conhecimentos que os estudantes podem ter:

Acredito que os alunos possivelmente possuam concepções mais próximas de física aristotélica, podendo ficar confusos com o heliocentrismo, geocentrismo. (Licenciando B, passo final) 
Relação entre força e movimento, ou seja, acreditar que as forças que interagem em um corpo só irão existir se ele estiver em movimento, pares de ação e reação que só irão em corpos distintos, relação sobre a ideia sobre inércia (movimento e repouso). (Licenciando $P$, passo final)

Percebemos, nas respostas dos licenciandos, um amadurecimento maior com relação os conhecimentos prévios que os estudantes possuem, pois o entendimento do licenciando $P$, com relação ao conhecimento dos estudantes, sobre o conceito de força, vai ao encontro do que se relata na literatura, a partir de pesquisas com estudantes. De acordo com Driver et al (1999), uma das áreas mais exaustivamente estudadas é o raciocínio informal sobre mecânica. Nesta área existe uma concepção comum de que é necessária uma força constante para manter um objeto em movimento constante.

Com relação à cosmologia e movimento dos astros:

Os alunos geralmente chegam em sala de aula com pensamento, conhecimentos prévios, de que as estações do ano ocorrem devido a proximidade do planeta ao sol, e essa questão era as mudanças das estações mais quentes para as mais frias. (Licencianda L, passo final)

Acredito que apesar de tratar de fenômenos presentes no dia-a-dia dos alunos, poucos ou nenhum deles saberiam explicar corretamente as causas de fenômenos, como fases da lua e estações do ano. Muitos com certeza confundem e misturam as explicações a respeito de ocorrência de eclipses com as fases da lua, por exemplo. (Licenciando F, passo final)

Percebemos aqui, que o trabalho realizado ao longo da disciplina, contribuiu com essa mudança de postura, visto que, umas das atividades solicitadas estimulava a pesquisa na literatura por concepções alternativas dos estudantes e de formas de apresentar o conteúdo.

Assim, como afirma Driver et al (1999), em vez de construir uma única e poderosa ideia, os indivíduos podem apresentar maneiras diferentes de pensar, ou seja, um perfil conceitual dentro de domínios específicos.

Dessa forma, os licenciandos aproximam-se novamente de modelos didáticos mais desejáveis de ensino, pois, assim como afirma Garcia (1999), neste modelo a aprendizagem é vista como um processo de integração e reelaboração progressiva dos próprios conhecimentos. Considera-se que os alunos podem ter conhecimentos próprios sobre os conteúdos, porém se considera que esses conhecimentos evoluem por interação com outros conhecimentos, com outros sujeitos e com o meio próximo em geral.

$\mathrm{Na}$ segunda categorização, reunimos as respostas dos licenciandos sobre como trabalhariam a partir de e com os conhecimentos prévios dos estudantes. As US estão apresentadas na tabela 2 . 
Tabela 2: US dos passos inicial e final da categoria formas de trabalhar com os conhecimentos prévios dos alunos.

\begin{tabular}{|l|l|}
\hline \multicolumn{2}{|c|}{ Categoria: formas para trabalhar com os conhecimentos prévios dos alunos } \\
\hline \multicolumn{1}{|c|}{ US passo inicial } & \multicolumn{1}{c|}{ US passo final } \\
\hline Perguntas relacionadas ao cotidiano $(B, P, F, G)$ & Situações problema $(G, F)$ \\
Questionários $(L)$ & Mapa conceitual $(G, B, L, T)$ \\
Estudo de caso $(T)$ & Esquemas de desenhos $(G, B, P)$ \\
& Relação com o cotidiano ( $G, P)$ \\
& Questionários (B, $P, L, F)$ \\
\hline
\end{tabular}

No passo inicial, ao serem interrogados sobre como acessariam os conhecimentos prévios dos estudantes, os licenciandos emitem as seguintes respostas:

Perguntas sobre exemplos do dia-a-dia envolvendo o tópico em questão. Eu incluiria nas aulas explicações sobre as concepções erradas mais comuns. (Licenciando B, passo inicial)

Levaria exemplos cotidianos de situações relacionadas, perguntando sempre se eles sabem o que esta acontecendo ali e porque[...].Me focaria no que eles dissessem que sabiam e organizaria as aulas de uma forma que caso eles estivessem errados ou não soubessem iriam aprender o que acontece sozinhos ou isso estivessem certos detalharia mais os conhecimentos aumentando os assim (Licenciando G, Passo inicial)

Discutiria com os alunos questões do dia a dia apresentando até problemas e exigindo dos alunos soluções baseadas em seus conhecimentos prévios passaria para os alunos o filme em que a lua tem sua órbita alterada e começa a orbitar mais próximo a Terra causando perturbações devido ao seu campo gravitacional em seguida verificar a opinião dos alunos a respeito. Em cima dos conhecimentos prévios dos alunos eu analisaria as principais deficiências e os assuntos que thes despertem maior interesse, para serem aprofundados nas aulas seguintes. Após a exposição dos conteúdos apresentaria novamente as questões citadas no item anterior como forma de avaliar a evolução dos alunos. (Licenciando F, passo Inicial)

Nas respostas dos licenciandos, podemos notar dois aspectos importantes. O primeiro deles diz respeito à relação dos conhecimentos prévios dos alunos com o cotidiano, pois, de acordo com Pozo e Crespo (1998), o problema está no modo como pode haver essa articulação entre conhecimento prévio e novo, visto que muitas vezes, o conhecimento do cotidiano é distante daquele científico. Ainda segundo estes autores, as concepções prévias não são simples informações que o aluno adquire no seu cotidiano, mas representações da realidade, fundamentadas em suas experiências mais diretas.

O segundo aspecto refere-se aos indícios que os licenciandos deixam em suas respostas, de que estas ideias não precisam ser acessadas por acreditarem estarem erradas. Essas respostas mostram que os licenciandos apresentam concepções características do modelo tecnológico, visto que, os futuros docentes compreendem que os alunos têm conhecimentos prévios sobre os conteúdos, mas eles costumam ser errados. A aprendizagem ocorreria quando as mesmas fossem substituídas pelo conhecimento acadêmico correto. Nessa concepção, os conhecimentos dos alunos parecem ser consideradas como um conhecimento "inferior" ao conhecimento disciplinar. Em uma variante bem ativista dessa concepção, parte-se do princípio de que o sujeito deve 
implicar-se ativamente na aprendizagem e ser capaz de relacionar a nova informação com seus conhecimentos anteriores, porém, como resultado, ele deve construir exatamente aqueles significados previamente definidos. Desse modo, estas são consideradas como erros que devem ser substituídos por conhecimentos adequados (GARCIA PÉREZ, 2000).

Ainda no passo inicial, identificamos outros instrumentos que os licenciandos utilizariam para acessar estes conhecimentos:

Buscaria o auxilio de questionários direcionados e uma forma de jogos que desvende os pensamentos deles, de forma a interagi-lo e deixá-lo à vontade para tal. Os conhecimentos representam suas vontades, então se encontrar o equilíbrio entre os conhecimentos e o currículo proposto ao professor, a aula acaba sendo programada de uma forma que a probabilidade de envolver o aluno é maior. (Licencianda L, passo inicial)

Um estudo de caso seria um bom instrumento para saber o nível de conhecimento deles. Com base no estudo de caso elaboraria as aulas de modo a sanar suas curiosidades.

\section{(Licenciando T, passo inicial)}

Percebemos que já no passo inicial, os licenciandos apresentam instrumentos mais adequados para identificar os conhecimentos prévios dos estudantes. No passo final, percebemos que os licenciandos apresentam recursos mais consistentes para trabalhar com os conhecimentos prévios dos estudantes:

Perguntas diretas, esquemas desenhados, mapa conceitual, levar o conteúdo ao cotidiano, criar pequenos debates entre os alunos para levá-los a pensar por si próprios como funciona o questionando. Colocar o conteúdo no cotidiano e a partir disto fazer com que os próprios alunos se questionem sobre isto e procurem através de seus próprios conhecimentos compreenderem isto (conhecimentos colaborados comigo para que seja construída a resposta). (Licenciando $\mathrm{G}$, passo final)

Questionário, relacionando os conhecimentos prévios, mas não só um questionário com respostas, mas com desafios. Pedir para que os alunos realizem um desenho, solicitar que os alunos tragam relação e aplicação dos conceitos com o seu cotidiano. Faria um levantamento dos dados obtidos com os alunos e faria um planejamento visando confrontar as concepções deles com alguma dificuldade que viria a surgir. (Licenciando $P$, passo final)

Formularia um questionário para os alunos responderem em duplas, depois de respondido, discutiria com os alunos suas respostas e concepções iniciais. Criaria situações problemas para que os alunos resolvessem, em cima das questões em que eles encontravam mais dificuldade, para que os alunos cheguem à conclusão de que para resolver o problema precisam mudar seus conceitos, construindo assim o conceito correto. (Licenciando F, passo final)

A partir das respostas dos licenciados, podemos notar que a atitude que tomariam em suas aulas aproxima-se de um modelo mais desejável, o investigativo, pois neste modelo, a metodologia 
é baseada na investigação escolar do aluno, o trabalho é realizado em torno de problemas, com uma sequência de atividades relativas ao tratamento destes problemas. Desse modo, o aluno tem papel ativo como construtor e reconstrutor de seu conhecimento (PORLÁN E RIVERO, 1998).

Além disso, em suas respostas, assinalam que promoveriam estratégias que conduzissem a construção de conceitos, sinalizando novamente para o modelo desejável, no qual a aprendizagem de novos conceitos dá sentido ao seu mundo de significados e reorganiza o seu próprio sistema de ideias. Desse modo, a nova informação deve ser interpretada pelo sujeito que aprende e deve integrar-se à determinados sistemas de ideias, que estariam em contínua reestruturação (GARCIA PEREZ, 2000).

\section{CONSIDERAÇÕES FINAIS}

Apresentamos, neste trabalho, os resultados de um estudo de caso que versou sobre as concepções de futuros professores de Física a respeito das formas de acessar e considerar os conhecimentos dos estudantes em suas aulas. Estes conhecimentos encontram-se no centro dos problemas de aprendizagem, apresentando um relativo consenso de que o aluno não pode ser considerado com uma "mente em branco". Entretanto, de acordo com Harres et al, (2008), são as raras as investigações nas quais os conhecimentos dos alunos protagonizam as concepções e práticas dos professores.

Um aspecto relevante da análise deve-se ao fato de que os futuros professores, no passo final do estudo de caso, ou seja, ao fim da proposta didática implementada na disciplina, conseguiram evoluir em suas concepções, ultrapassando modelos mais tradicionais para modelos mais próximos do desejável, neste caso, o modelo investigativo. Esse modelo leva em consideração os interesses e os conhecimentos dos alunos, tanto em relação ao conhecimento proposto, como em relação com a construção do conhecimento (PORLÁN E RIVERO, 1998).

Ao retomarmos a questão de pesquisa: como os futuros professores podem evoluir seus conhecimentos didático-metodológicos e adquirir meios para que esta evolução seja capaz de proporcionar mudanças em suas práticas? Percebemos que as análises mostraram a importância do método de estudo de caso como estratégia de ensino, pois permite ao professor/pesquisador e ao próprio licenciando perceber o progresso na conceituação dos temas debatidos. Acreditamos que o aprofundamento destas questões, em uma proposta curricular focalizando momentos de prática e reflexão, pode oportunizar aos futuros docentes os primeiros passos em direção a uma postura crítica, reflexiva, aberta a mudança e em permanente evolução do conhecimento profissional. Logo, os resultados obtidos podem servir de referência para a implementação de estratégias para a formação docente na área de Física, bem como de outras áreas da Ciência na Educação Básica, na medida em que esses estudos propiciem um melhor conhecimento sobre os processos de evolução do conhecimento dos professores.

\section{REFERÊNCIAS}

1. BARDIN, L. Análise de Conteúdo.Lisboa: Edições 70, 2009.

2. BATISTA, I.L. e ARAMAN, E.M.O. (2009). Uma abordagem históricopedagógicapara o ensino de Ciências nas séries iniciais do EnsinoFundamental. Revista Electrónica de Enseñanza de 
lasCiencias, 8, 2, 466-489.

3. BRASIL, Ministério da Educação. Secretaria de Educação Média e Tecnológica. Parâmetroscurriculares nacionais para o ensino médio. Brasília, 1999.

4. BORGES, O., Formação inicial de professores de física: Formar mais! Formarmelhor! Revista Brasileira de ensino de Física, v. 28, n. 2, p. 135-142, 2006.

5. DELIZOICOV, D.; ANGOTTI, J. A.; PERNAMBUCO, M. M. Ensino de Ciências: fundamentos e métodos. Coleção: Docência em formação. São Paulo: Cortez, 2002. 366p.

6. GARCÍA, J. E. Las ideas de los alumnos. Cuadernos de Pedagogía, 276: 58-64, 1999.

7. GARCíA, J.E.; Porlán, R. Teoria e prática na ação docente. Cad. Pedagógicos, 3, 7-42, Lajeado, 2000.

8. GARCÍA PÉREZ, F. F. Los modelos didácticos como instrumento de análisis y de intervención em la realidad educativa. Biblio3W: revista bibliográfica de geografíaycienciassociales, Barcelona, n. 207, feb. 2000. Disponível em: <http://www.ub.es/geocrit/b3w-207.htm>. Acesso em: 20 maio 2007.

9. GENEZINI, F., A.; PIRES, C.A.; SILVA, E. A.; PRADO, A.P.; COSTA, A.O. Estudo de concepções alternativas no ensino médio,Anaisdo XVI Simpósio nacional de Ensino de Física, 2007.

10. GUIMARÃES, M. A. G.; ECHEVERRÍA A. R. \& MORAES J. I. Modelos didáticos no discurso de professores de Ciências. Revista Eletrônica de Investigação em Ensino de Ciências, Porto Alegre, v. 11, n. 3, 2006.

11. HARRES, J.B.S.; PIZZATO, M.C. ; HENZ, T.; FONSECA, M.C.; PREDEBON, F.; SEBASTIANY, A.P. (Org.) Laboratórios de Ensino: inovação curricular na formação de professores de ciências. Santo André (SP): ESETec Editores Associados. 2005, 99 p.

12. _ PIZZATO, M.C. SEBAstiany, A. P. PREDEBON, F. FONSECA, M.C. Evolução das concepções de futuros professores sobre a natureza e as formas de conhecer as ideias dos alunos, Revista Brasileira de Ensino de Ciência e Tecnologia, v.1, n.2, 2008.

13. HYGINO, C.B; MOURA, S.A.; LINHARES, M.P.; Modelos didáticos na formação inicial de professores de física: uma apreciação na perspectiva da análise do discurso, Ciência e Educação, v. 20, n. 1, p. 43-59, 2014.

14. ___ _L LINHARES, M.P. Concepções alternativas e abordagens em sala de aula sobrecosmologia e movimento dos astros: Uma revisão da literatura do contexto brasileiro, Anais do XX Simpósio Nacional de Ensino de Física - SNEF 2013 - São Paulo, SP.

15. IACHEL, G.; LANGHI, R.; SCALVI, R. M. F. Concepções alternativas de alunos doensino médio sobre o fenômeno da formação das fases da lua. Revista Latino-Americana de Educação em Astronomia - RELEA, n.5, p. 25-37, 2008.

16. KRUMMENAUER, W.L,Situações cotidianas de dilatação térmica como motivação ao estudo deste tema no $9^{\circ}$ ano do ensino fundamental, Experiências em Ensino de Ciências, v. 5, n.3, p. 47-53, 2010.

17. MOREIRA, M. A., Pesquisa em Educação em Ciências: Métodos qualitativos, Programa Internacional de Doctorado em Enseñanza de lasCiencias. Universidad de Burgos, Espanha; Universidade Federal do Rio Grande do Sul, Brasil. Texto de Apoio $n^{\circ} 14$. Publicado em Actas del PIDEC, 4:25-55, 2002. 
18. MORTIMER, E.F. Construtivismo, mudança conceitual e ensino de ciências: para onde vamos? Investigações em Ensino de Ciências, 1(1):20-39, 1996.

19. OLIVEIRA, O. B. Reflexões sobre a escrita na formação inicial de professores. Educar, Curitiba, n. 34, p. 111-126, 2009.

20. PORLÁN.R.; RIVERO, A. (1998) El conocimiento de los profesores. Díada: Sevilla.

21. POZO, J. I. M; CRESPO, M. A. G. Aprender y enseñar ciência: Del conocimiento cotidiano al conocimiento científico. Madrid: Ediciones Morata. 1998. 330p.

22. REIS, E.M; LINHARES, M. P. Estudos de caso como estratégia de ensino naformação de professores de física. Ciência e Educação, Bauru, v.14, n.3, p. 555-74, 2008.

23. SEBASTIANY, A.P. DIEHL, I.F. HARRES, J.B.S.PIZZATO, M.C., Análise das ideias dos alunos sobre hidrostática, Física na Escola, v. 10, n. 2, 2009.

24. DRIVER, R. ASOKO, H. LEACH, J. MORTIMER, E. SCOTT, P. Construindo Conhecimento Científico na sala de aula, QUÍMICA NOVA NA ESCOLA, n. 9, 1999. 